\title{
Oursbelille-Maubourguet (Hautes-pyrénées)
}

\section{Suzanne Tison}

\section{OpenEdition \\ Journals}

Édition électronique

URL : http://journals.openedition.org/adlfi/10554

ISSN : 2114-0502

Éditeur

Ministère de la culture

Référence électronique

Suzanne Tison, "Oursbelille-Maubourguet (Hautes-pyrénées) », ADLFI. Archéologie de la France Informations [En ligne], Midi-Pyrénées, mis en ligne le 01 mars 1997, consulté le 26 avril 2019. URL http://journals.openedition.org/adlfi/10554

Ce document a été généré automatiquement le 26 avril 2019

(C) Ministère de la Culture et de la Communication, CNRS 


\title{
Oursbelille-Maubourguet (Hautes- pyrénées)
}

\author{
Suzanne Tison
}

Date de l'opération : 1991 (PI)

Inventeur(s) : Tison Suzanne

1 Le projet de création d'un gazoduc permettant l'alimentation en gaz naturel de la vallée de l'Adour, a permis de réaliser une prospection-inventaire suivie d'une surveillance des travaux. L'état des connaissances étant très fragmentaire, surtout au-delà de Maubourguet, il est apparu nécessaire de compléter notre information, les tranchées servant alors de sondages d'évaluation pour un futur projet de déviation.

2 En dehors de quelques fragments de céramiques antiques et médiévales recueillis sur le tracé, dans les communes d'Oursbelille, Gayan, Siarrouy et qui ne permettent pas d'établir avec certitude l'existence de gisements, l'essentiel des informations a été relevé à Pujo et à Vic-en-Bigorre, Saint-Aunis (tegulae, amphores Pascual 1 et Dr.2/4, céramiques communes), elles marquent la présence d'établissements gallo-romains du Haut-Empire.

Mais l'intérêt de cette opération réside notamment dans la découverte d'un dépotoir du Haut Moyen Âge (?) à proximité du site du Bourg-Vieux, implantation initiale de Maubourguet, abandonné, d'après les textes des $\mathrm{XI}^{\mathrm{e}} \mathrm{s}$. et $\mathrm{XII}{ }^{\mathrm{e}} \mathrm{s}$., au profit de son emplacement actuel autour du prieuré de Saint-Martin-de-Celle.

4 Les céramiques mises au jour (essentiellement des pots globulaires, parfois décorés de cordons digités) suggèrent au fouilleur une datation comprise entre le $\mathrm{VI}^{\mathrm{e}} \mathrm{s}$. (?) et le $\mathrm{XI}^{\mathrm{e}} \mathrm{s}$. Compte tenu des faibles données typochronologiques avancées, il nous parait prématuré d'établir une liaison directe avec le Haut Moyen Âge. 
INDEX

Index chronologique : Antiquité romaine, Moyen Âge*, Haut-Empire Index géographique : Midi-Pyrénées, Hautes-Pyrénées (65), Oursbelille operation Prospection inventaire (PI) 